\title{
Electrolytic Polishing Test and Surface Properties of Nitinol Tube
}

\author{
Hua $\mathrm{Ji}^{1}$, Yongqi Wang $^{2}$, Zhiyong $\mathrm{Li}^{2,{ }^{*},}$, Zhaoxia Huang ${ }^{2}$, Mingxia Chai $^{2}$ \\ ${ }^{1}$ Shandong University of Technology, School of Electrical and Electronic Engineering, 266 xincun \\ west road, 255049, Zibo, China \\ ${ }^{2}$ Shandong University of Technology, School of Mechanical Engineering, 266 xincun west road, \\ 255049, Zibo, China \\ *E-mail: Lzy761012@ sdut.edu.cn
}

doi: $10.20964 / 2021.03 .42$

Received: 13 October 2020 / Accepted: 25 December 2020 / Published: 31 January 2021

\begin{abstract}
Nitinol alloy is widely used in biomedicine because of its tensile resistance, fatigue resistance, shape memory effect, and good biocompatibility. This study aims to utilize an electrolytic polishing method to improve the surface condition of nitinol tubes. The electrolyte ratio of a basic electrolytic polishing solution was explored. Orthogonal and single-factor experiments were performed to determine the effects of four electrolytic polishing factors, namely, current density, polishing time, distance between electrodes, and polishing temperature, on the surface morphology of nitinol. The best combination of electrolytic polishing process parameters was then identified. Finally, changes in the surface roughness, surface morphology, and hydrophobicity of nitinol before and after electrolytic polishing were compared.
\end{abstract}

Keywords: Nitinol tube; Electrolytic polishing; Surface morphology; Surface roughness

\section{$\underline{\text { FULL TEXT }}$}

(C) 2021 The Authors. Published by ESG (www.electrochemsci.org). This article is an open access article distributed under the terms and conditions of the Creative Commons Attribution license (http://creativecommons.org/licenses/by/4.0/). 